\title{
A complex finite-element model for the investigation of historical masonry
}

\author{
J. Maděra, J. Kočí \& R. Černý \\ Department of Materials Engineering and Chemistry, \\ Faculty of Civil Engineering, Czech Technical University in Prague, \\ Czech Republic
}

\begin{abstract}
A finite-element model is applied for the calculation of temperature and relative humidity fields in three characteristic types of historical masonry. The complex finite-element mesh of the studied cross-sections is generated by commercial software GID and then the simulations are performed using computational tool SIFEL. To each material in the cross section, the respective material characteristics are assigned. In the same way, the materials are covered by finiteelement mesh. The computational results are used to assess the long-term hygrothermal performance of particular historical walls. The presented results show that some types of historical walls can be modeled using simplified homogenization methods.
\end{abstract}

Keywords: finite element method, heat and moisture transport, historical masonry.

\section{Introduction}

The historical buildings are considered in most civilized nations to be one of the most valuable heritages from past generation and cultures. In some cases, we talk about objects of incalculable values. The renovations of this kind of buildings must be done with delicate approach and of course the price of such renovation is expected to be very high. The renovation processes are mostly controlled by monument care authorities, which insist on preservation of original treatments, technologies and materials from the period of the building's rise. Unfortunately some materials do not exist anymore and therefore they must be replaced by new modern ones with same or similar properties. The supervising authorities usually 
choose such material that was suitable at some other similar application before. The replacement of "extinct" materials is one of the most important steps in renovation process [1]. Another way, how to avoid possible problems in a material choice is involving a computational analysis into designing process of the renovation. Based on that analysis the composition of building envelope and interaction between the materials can be assessed in advance.

The basic problem of most historical objects is a presence of moisture in the load-bearing structure, especially in a liquid form. A lack of knowledge of hygric or hygrothermal behavior of renovated construction may lead to its serious damage. Usually this damage is obvious in a long time after the renovation. A typical source of mechanical damage is desiccation of a mortar, material degradation or a change of hydrogeological conditions in the underground soil.

There are two different approaches in modeling of load-bearing structures, whether we talk about mechanical or hygrothermal models. The first approach uses utilization of effective media theory. These homogenization principles are usually used for mechanical modeling of a historical masonry with a regular brick composition [2-4]. Application of homogenization principles in coupled heat and moisture transport was investigated by Sýkora et al. [5, 6]. A valuable example of an application of this approach can be found in the renovation of the Charles Bridge in Prague. Here, both mechanical [7] and coupled heat, moisture and momentum transport models [8] were employed. The solutions of such big computational problems place high demands on hardware equipment. These high demands are usually met by involving parallel computing, which was described in detail, e.g., by Kruis [9].

Another approach, mentioned in this article, consists in modeling of the construction with the real composition, i.e., with respective material parameters of mortar and brick/stone. A coupled heat, moisture and momentum transport model for the investigation of masonry with a regular composition was employed by Ramézani and Jeong [10].

In this paper, three load-bearing materials (brick, argillite and sandstone) with three different structures of the masonry were chosen for computer simulations.

\section{Computational analysis}

\subsection{Computational tool and numerical model}

The numerical analysis of transport processes in porous building materials was accomplished using computational tool SIFEL [11], which uses simple element methods to solve partial differential equations of coupled heat and moisture transport. In the particular case in this paper, Kunzel's mathematical model was used [12]:

$$
\frac{d \rho_{v}}{d \varphi} \frac{\partial \varphi}{\partial t}=\operatorname{div}\left[D_{\varphi} \operatorname{grad} \varphi+\delta_{p} \operatorname{grad}\left(\varphi p_{s}\right)\right]
$$




$$
\frac{d H}{d T} \frac{\partial T}{\partial t}=\operatorname{div}(\lambda \operatorname{grad} T)+L_{v} \operatorname{div}\left[\delta_{p} \operatorname{grad}\left(\varphi p_{s}\right)\right]
$$

where $\rho_{v}$ is the partial density of moisture, $\varphi$ relative humidity, $\delta_{p}$ permeability of water vapour, $\mathrm{p}_{\mathrm{s}}$ partial pressure of saturated water vapour, $\mathrm{H}$ enthalpy density, $L_{v}$ heat of evaporation, $\lambda$ thermal conductivity and $T$ temperature

$$
D_{\varphi}=D_{w} \frac{d \rho_{v}}{d \varphi}
$$

is liquid moisture diffusivity coefficient, $D_{w}$ capillary transport coefficient.

\subsection{Material parameters}

For the computational analysis three load-bearing materials with one mortar were chosen (burnt ceramic brick, sandstone and argillite).

Burnt ceramic brick produced by brick factory Žopa, Czech Republic was the first analysed walling material. It is highly heterogeneous material that varies in colour, grains' and pores' distribution. This material was chosen for the research because of its similarity with historical bricks originally applied in Central European territory for religious as well as secular architecture [17].

Second investigated material, the sandstone, comes from quarry Mšené in the Czech Republic. Many historical buildings in Czech region were built using similar kinds of sandstone. It is psamitic equigranular rock, about $95 \%$ of which is made up of suboval quartz clasts. Other mineral grains are present only as accessories (tourmaline, epidote, muscovite and zircone). Quartz grains reach up to $0.1 \mathrm{~mm}$ in diameter, but those of muscovite are larger, up to $0.3 \mathrm{~mm}$. The matrix is formed by clay minerals (mainly kaolinite) [17].

The last material, argillite, comes from quarry Džbán in the Czech Republic. Argillite was very popular material in historical architecture. It was used for sacral as well as for secular buildings, flagstone pavements, roof slabs, and facing. The studied argillite constituents are illite, calcite, minerals on the basis of $\mathrm{SiO}_{2}$ having granularity $0.3-0.15 \mathrm{~mm}$, feldspar, and mica, whereas rigid materials form $40-60 \%$ of argillite volume [16].

As the composition of historical mortars is unavailable, we used binding material on lime-pozzolana basis, which is one of the most favorite of conservationists [13].

All the material parameters were measured in the laboratory of transport processes at the Department of Materials Engineering and Chemistry, Faculty of Civil Engineering, Czech Technical University in Prague [14-17] and are summarized in Table 1 . We used these symbols: $\rho-$ bulk density $\left[\mathrm{kg} / \mathrm{m}^{3}\right]$, $\psi$ - porosity [\%], $c$ - specific heat capacity $[\mathrm{J} / \mathrm{kgK}], \mu$ - water vapour diffusion resistance factor [-], $w_{\text {hyg }}-$ hygroscopic moisture content by volume $\left[\mathrm{m}^{3} / \mathrm{m}^{3}\right], \lambda-$ thermal conductivity $[\mathrm{W} / \mathrm{mK}], \kappa_{a p p}-$ apparent moisture diffusivity $\left[\mathrm{m}^{2} / \mathrm{s}\right]$. 
Table 1: $\quad$ Material characteristics.

\begin{tabular}{|c|c|c|c|c|}
\hline & $\begin{array}{c}\text { Sandstone }- \\
\text { Mšené }\end{array}$ & Argillite & $\begin{array}{c}\text { Historical } \\
\text { brick }\end{array}$ & Mortar \\
\hline \hline$\rho\left[\mathrm{kg} / \mathrm{m}^{3}\right]$ & 1807 & 1353 & 1670 & 1690 \\
\hline$\psi[\%]$ & 30.2 & 39.0 & 36.1 & 34.1 \\
\hline$c[\mathrm{~J} / \mathrm{kgK}]$ & 675 & 1074 & 1202 & 877 \\
\hline$\mu_{\text {dry cup }}[-]$ & 6.98 & 5.66 & 19.5 & 29.03 \\
\hline$\mu_{\text {wet cup }}[-]$ & 5.5 & 4.1 & 14.7 & 11.57 \\
\hline$\lambda_{\text {dry }}[\mathrm{W} / \mathrm{mK}]$ & 0.4 & 0.428 & 0.5 & 0.886 \\
\hline$\lambda_{\text {sat }}[\mathrm{W} / \mathrm{mK}]$ & 0.65 & 0.968 & 1.2 & 2.19 \\
\hline$\kappa_{\text {app }}\left[\mathrm{m}^{2} / \mathrm{s}\right]$ & $1.70 \mathrm{e}-05$ & $5.29 \mathrm{e}-08$ & $2.65 \mathrm{e}-7$ & $2.01 \mathrm{e}-7$ \\
\hline$w_{\text {hyg }}\left[\mathrm{m}^{3} / \mathrm{m}^{3}\right]$ & 0.011 & 0.128 & 0.0804 & 0.049 \\
\hline
\end{tabular}

\subsection{Schemes of construction details}

Figs 1-3 show characteristic load-bearing constructions, typical for historical objects. The studied detail was meshed by the commercial software GID 11 [18]. Apparently, the generated finite-element mesh of mortar was finer than a stone's/brick's one. Thus, a higher accuracy of computer simulations was ensured, but on the other hand the hardware and time requirements for the computations were increased. The brick walling (Fig. 1), typical for its regular joints in both horizontal and vertical directions, consists of 6,054 elements. The construction thickness is $0.440 \mathrm{~m}$. The joint is $10 \mathrm{~mm}$ wide.

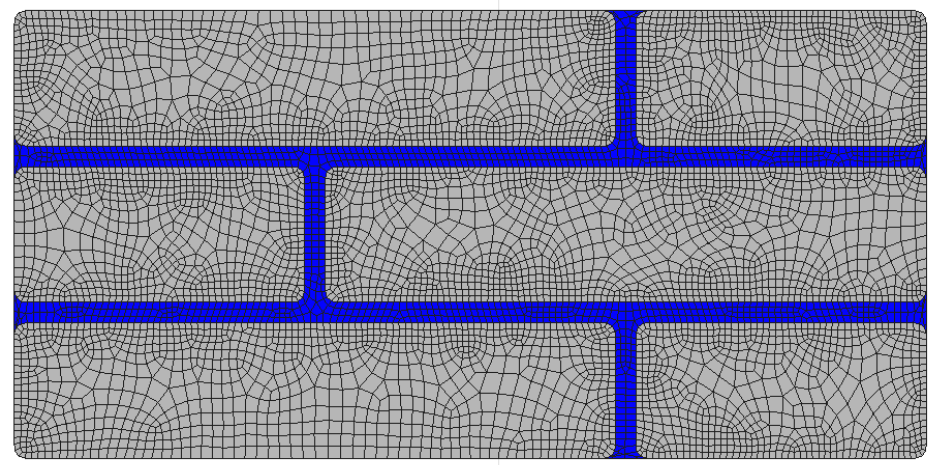

Figure 1: Example of brick masonry. 
The second historical wall is made from argillite (Fig. 2). The stonework masonry has a regular horizontal joints and bed joints. The vertical joins are irregular. The mesh consists of 11133 elements, the thickness of the wall is $1.0 \mathrm{~m}$ and the thickness of the joint is from 1 to $6 \mathrm{~cm}$.

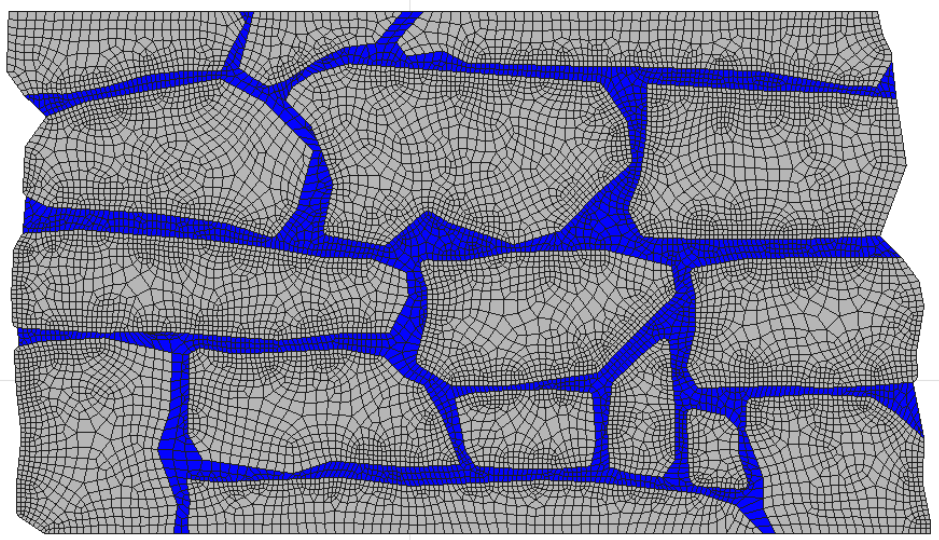

Figure 2: Example of argillite masonry.

The third stonework masonry is made from sandstone (Fig. 3). This masonry is typical for its irregularity. The space arrangement of the load-bearing material is very accidental. The thickness of the construction is about $1 \mathrm{~m}$ and the thickness of the joints varies between 1 and $8 \mathrm{~cm}$. The mesh consists of 11688 elements.

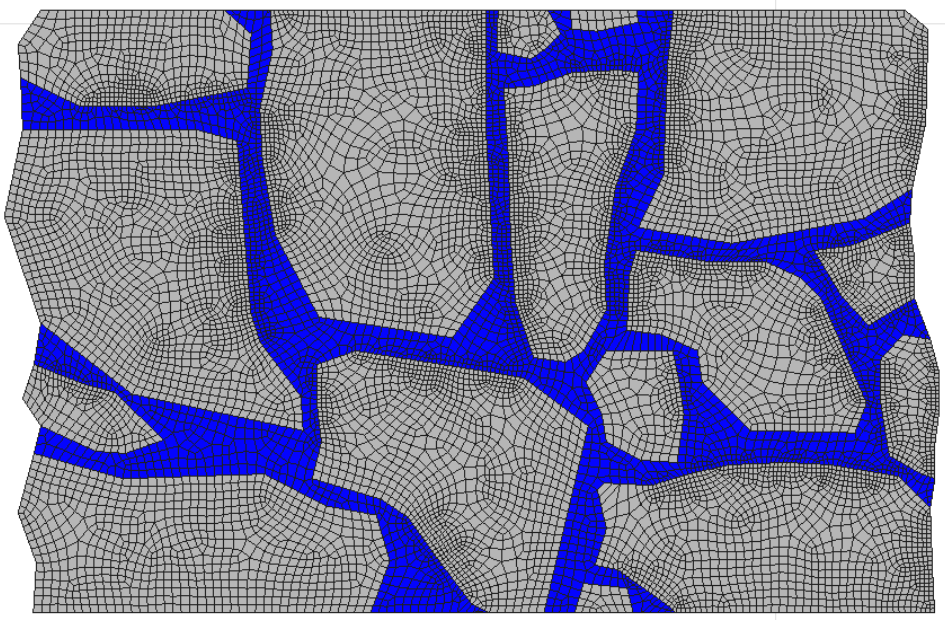

Figure 3: $\quad$ Example of sandstone masonry. 
Using finite element methods for solving non-stationary nonlinear problems requires setting of initial and boundary conditions. The initial temperature of all three types of historical masonry was set to $11^{\circ} \mathrm{C}$ and relative humidity to $60 \%$. The interior boundary conditions (on the left in the following figures) were set as constant to $21^{\circ} \mathrm{C}$ and $55 \%$ relative humidity. The exterior boundary conditions was defined using test reference year (TRY) for Prague, which presents a longterm average of hourly values of temperature, relative humidity, wind speed and direction, precipitation and solar radiation. The meteorological data was obtained using Meteonorm software [19].

\section{Results}

The results of performed computer simulations are shown in Figs. 4-9. The simulation outputs, such as temperature and relative humidity fields, were generated for $15^{\text {th }}$ December, year 5, as a representative day due to high level of moisture transport at low temperatures of the exterior air.

\subsection{Brick wall}

In Figs 4 and 5, there is apparent a uniform distribution of temperature and relative humidity. The heat transfer through joints and brick is very similar

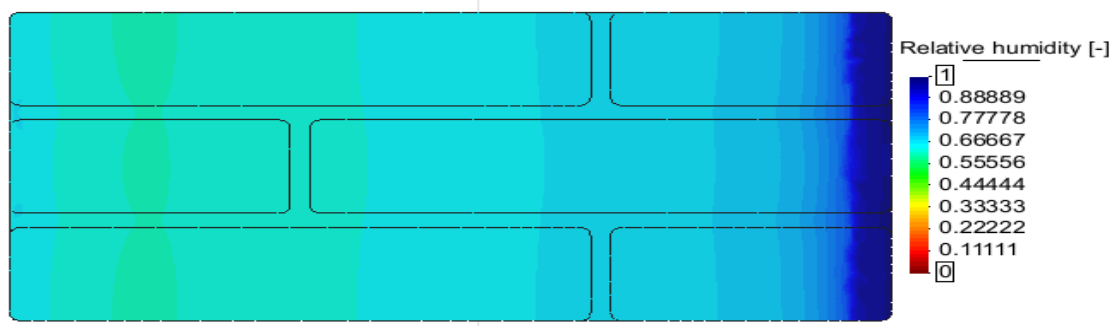

Figure 4: Relative humidity distribution in the brick wall, $15^{\text {th }}$ December.

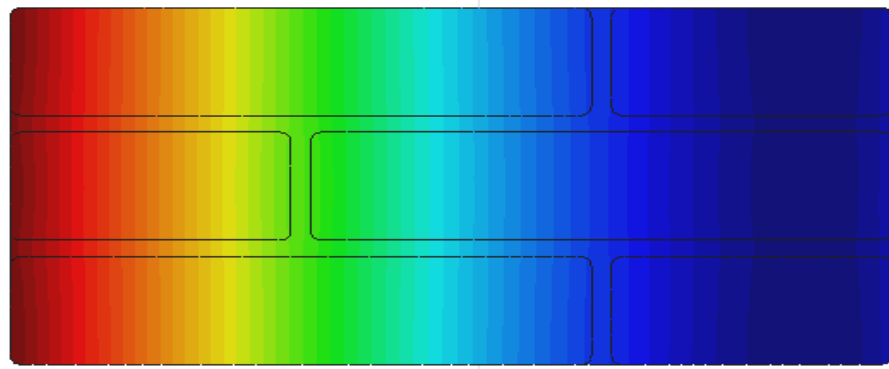

Figure 5: Temperature distribution in the brick wall, $15^{\text {th }}$ December. 
which is proven by parallel isolines in Fig. 5. The relative humidity transport is also very homogenous due to similar material properties. The differences of relative humidity of brick and mortar in the same position are less than $1 \%$ (Fig. 4).

\subsection{Argillite wall}

Contrary to the brick wall, the argillite wall exhibits higher differences in relative humidity distribution (Fig. 6). The transport rate of moisture in stone and mortar is different, which is given by its space arrangement and different material properties. The difference in relative humidity between stone and mortar in the same position is up to $3 \%$. The heat transfer is homogenous as in case of brick wall (Fig. 7).

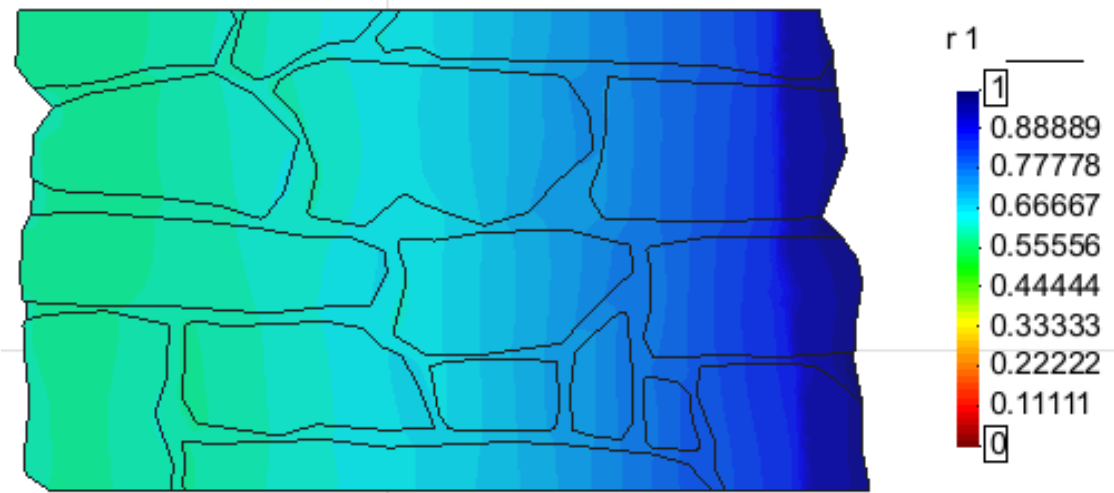

Figure 6: Relative humidity distribution in the argillite wall, $15^{\text {th }}$ December.
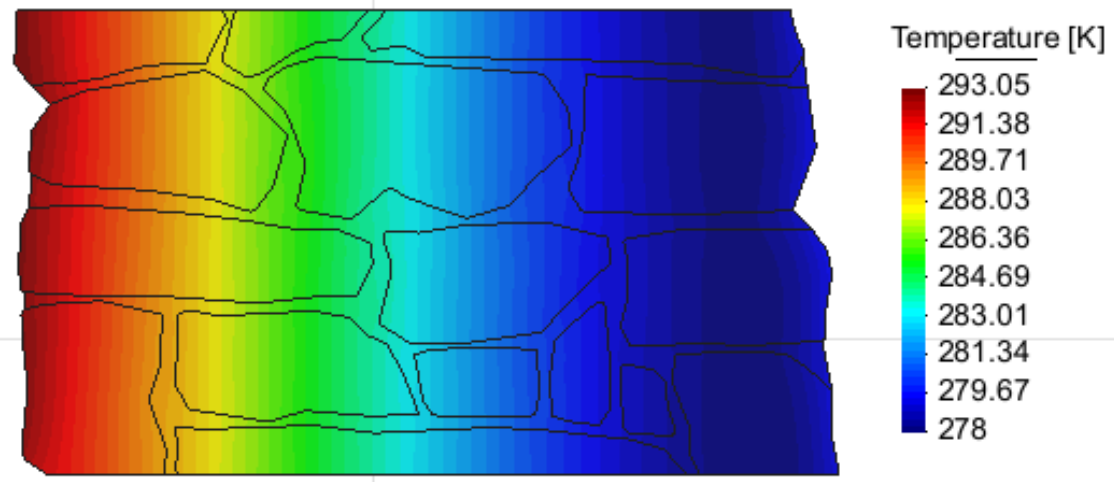

Figure 7: Temperature distribution in the argilite wall, $15^{\text {th }}$ December. 


\subsection{Sandstone wall}

The relative humidity distribution in sandstone wall is presented in Fig. 8. One can see the highest differences in moisture transport among all studied constructions. The difference in relative humidity between sandstone and mortar in the same position is up to $10 \%$. The main reason of those differences is given by different values of moisture diffusivities of sandstone and mortar, which is obvious in exterior layers, where the construction comes into direct contact with liquid water from precipitation.

As the simulations were accomplished for coupled heat and moisture transport, the inhomogeneous distribution of moisture has a certain effect on the distribution of temperature (Fig. 9). In case of sandstone wall, the differences are up to $2^{\circ} \mathrm{C}$ for the stone and mortar with same position.

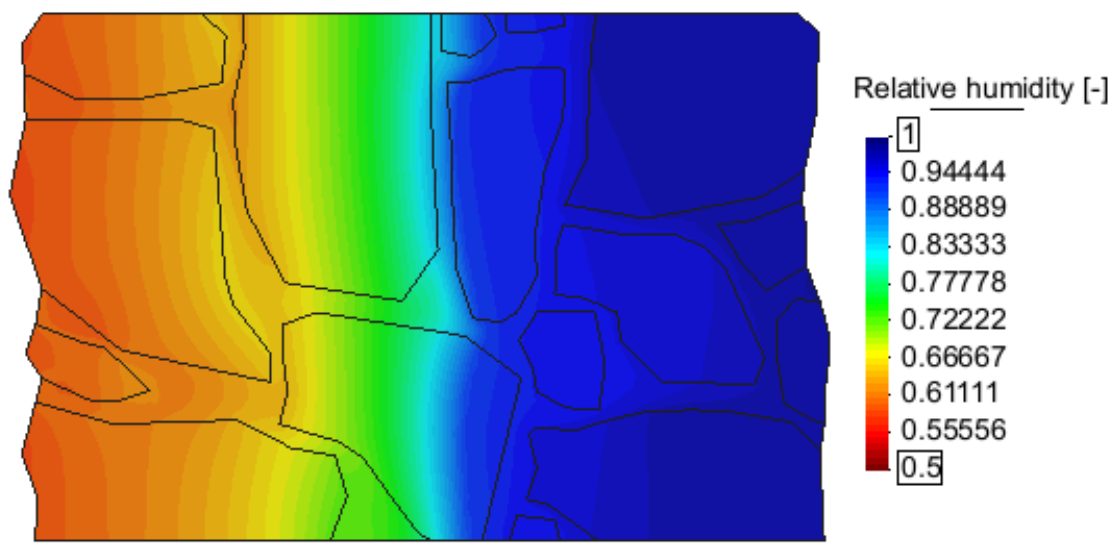

Figure 8: Relative humidity distribution in sandstone wall, $15^{\text {th }}$ December.

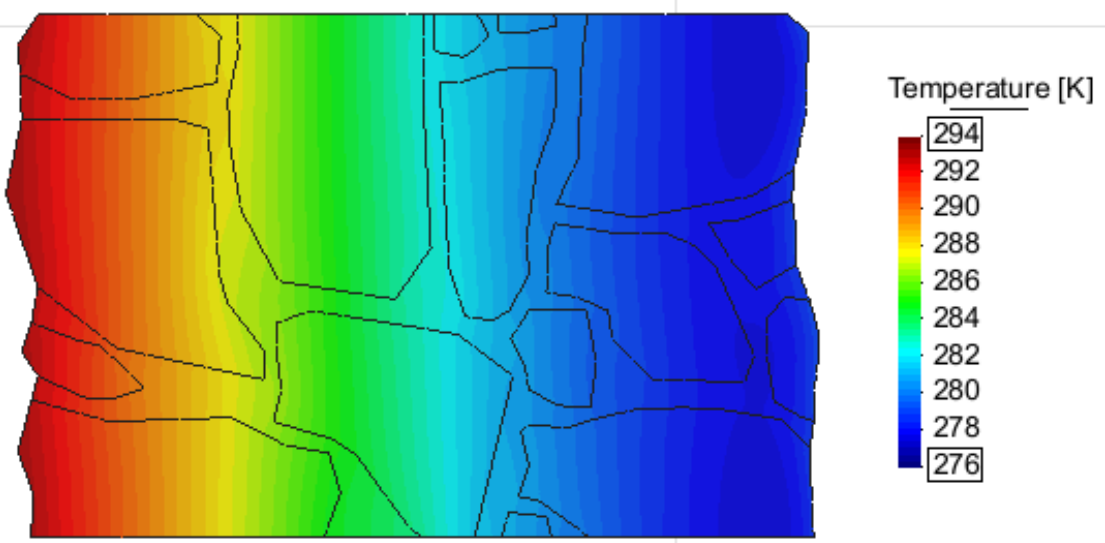

Figure 9: Temperature distribution in sandstone wall, $15^{\text {th }}$ December. 


\section{Discussion}

The perfect knowledge of hygrothermal behavior of building construction is a crucial factor for proper design of renovation or rehabilitation measures. Such knowledge is even more welcome in civil engineering.

Involving of the homogenization principles in moisture transport modeling may result in homogenous transport of the moisture in whole construction, which increases the risk of overlooking weak points in the construction. The determination of freeze/thaw cycles may serve as an example. The freeze/thaw cycle appears when two conditions are met, first there is a presence of liquid water and second, the temperature is under the water freezing point. To localize the exact parts of the construction with convenient conditions for water freezing, it is very unsuitable to use homogenization.

The first studied variant made from bricks and mortar is, according to presented results, quite suitable for using of homogenization principles. This conclusion can be explained by similar material properties of brick body and mortar, both for water vapor and liquid water transport. The regular structure of the brick wall also supports that conclusion.

The second investigated wall made of argillite exhibits small inhomogeneity in both heat and moisture transport. Even though it can be stated that involving of the homogenization is valuable. Again, the material properties of argillite and lime-pozzolana mortar are quite similar, especially for transport of liquid water. The effect of irregular structure is, due to similar material parameters, almost negligible.

The sandstone wall as the last investigated construction serves as a good example of inappropriate use of homogenization methods. The difference in apparent moisture diffusivity of sandstone and mortar is up to two orders of magnitude, so the moisture is primarily transported through sandstone (see Fig. 8).

If the temperature drops down below the freezing point, the mechanical damage of load-bearing material may occur. This would be undetected by modeling with effective media theory. Last but not least, the necessity for separate modeling of sandstone and mortar is supported by irregular composition of the wall.

\section{Conclusions}

The results presented in this paper showed that some types of historical masonry were suitable for modeling using effective media theory. For example the masonry made from historical bricks met all demands for using homogenization principles in heat and moisture transport modeling; on the other hand the sandstone masonry was for that kind of approach unsuitable.

The suitability of using homogenization principles in computational modeling depends on material composition of the construction and especially on the objective of the simulation, e.g., modeling of construction details or whole 
objects. In general, it can be stated that homogenization is more suitable for mechanical models.

\section{Acknowledgement}

This research has been supported by the Ministry of Culture of the Czech Republic, under project No DF12P01OVV030.

\section{References}

[1] Pavlík, Z., Pavlíková, M., Maděra, J. and Černý, R., New type of lime plaster with pozzolana admixture for renewal of historical buildings. Advanced Materials Research, 324 (1), pp. 336-339, 2011.

[2] Cecchi, A. and Tralli, A., A Homogenized Viscoelastic Model for Masonry Structures. International Journal of Solids and Structures, 49, pp. 14851496, 2012.

[3] Furtmüller, T., Adam, Ch., Numerical modeling of the in-plane behavior of historical brick masonry walls. Acta Mech, 221, pp. 65-67, 2011.

[4] Eslami, A., Ronagh, H.R., Mahini S.S. and Morshed, R., Experimental Investigation and Nonlinear FE Analysis of Historical Masonry Buildings A Case Study. Construction and Building Materials, 35, pp. 251-260, 2012.

[5] Sýkora, J., Vorel, J., Krejčí, T., Šejnoha, M. and Šejnoha, J., Analysis of coupled heat and moisture transfer in masonry structures. Materials and Structures, 42 (8), pp. 1153-1167, 2009.

[6] Sýkora, J., Šejnoha, M. and Šejnoha, J., Homogenization of Coupled Heat and Moisture Transport in Masonry Structures Including Interfaces. Applied Mathematics and Computation, (In press), http://dx.doi.org/10.1016 j.amc.2011.02.050.

[7] Zeman, J., Novák, J., Šejnoha, M. and Šejnoha, J., Pragmatic multi-scale and multi-physics analysis of Charles Bridge in Prague. Engineering Structures, 30, pp. 3365-3376, 2008.

[8] Sýkora, J., Krejčí, T., Kruis, J. and Šejnoha, M., Computational Homogenization of Non-stationary Transport Processes in Masonry Structures. Journal of Computational and Applied Mathematics, 236, pp. 4745-4755, 2012.

[9] Kruis, J., Domain decomposition methods on parallel computers. Progress in Engineering Computational Technology, ed. B. H. V. Topping and C. A. Mota Soares, Saxe-Coburg Publications, Stirling, Scotland, UK, pages 299322, 2004.

[10] Ramézani, H., Jeong, J., Environmentally Motivated Modeling of HygroThermally Induced Stresses in the Layered Limestone Masonry Structures: Physical Motivation and Numerical Modeling. Acta Mech, 220, pp. 107137, 2011.

[11] Kruis, J., Koudelka, T. and Krejčí, T., Efficient computer implementation of coupled hydro-thermo-mechanical analysis. Mathematics and Computers in Simulation, 80, pp. 1578-1588, 2010. 
[12] Künzel, H. M., Simultaneous Heat and Moisture Transport in Building Components, PhD Thesis, IRB Verlag Stuttgart, 1995.

[13] Kočí, J., Kočí, V., Maděra, J., Rovnaníková, P. and Černý, R., Computational analysis of hygrothermal performance of renovation renders. Advanced Computational Methods and Experiments in Heat Transfer XI. Southampton: WIT Press, pp. 267-277, 2010.

[14] Vejmelková, E., Máca, P., Konvalinka, P. and Černý, R., Innovative Limepozzolana Renders for Reconstruction of Historical Buildings. Advanced Materials Research, 324, pp. 372-375, 2011.

[15] Pavlík, Z., Fiala, L., Pavlíková, M. and Černý, R., Water and Chloride Transport Properties of Renovation Plasters Developed for Historical Masonry. 12th International Conference on Durability of Building Materials and Components. Porto: Faculdade de Engenharia da Universidade do Porto, pp. 745-752, 2011.

[16] Pavlík, Z., Vejmelková, E., Pavlíková, M., Keppert, M. and Černý, R., Characterization of Building Stones Involved in Historical Masonry. Advanced Materials Research, 324, pp. 388-391, 2011.

[17] Pavlík, Z., Fiala, L., Pavlíková, M., Pernicová, R. and Černý, R., Hygric and thermal properties of historical masonry. Structural Faults and Repair 2010 [CD-ROM]. Edinburgh: Engineering Technics Press Edinburgh, 2010.

[18] GID Version 11, International Center for Numerical Methods in Engineering, Spain, 2012.

[19] Meteonorm Version 6, software version 6.1.0.20 of April 2010, METEOTEST, Switzerland, 2010. 